\title{
A Bargaining Model of Tax Competition
}

\author{
Seungjin Han John Leach* \\ Department of Economics, McMaster University
}

December 4, 2007

\begin{abstract}
This paper develops a model in which competing governments offer financial incentives to induce individual firms to locate within their jurisdictions. Equilibrium is described under three specifications of the supplementary taxes. There is no misallocation of capital under two of these specifications, and there might or might not be capital misallocation under the third. This result contrasts strongly with that of the standard tax competition model, which does not allow governments to treat firms individually. That model finds that competition among governments almost always leads to capital misallocation.
\end{abstract}

\section{Introduction}

The tax competition literature assumes that the economy is divided into autonomous regions, and that capital can move freely between the regions. Its objective is to determine the rates at which the regions will tax profits, and the impact of the profits tax on resource allocation. It finds that the

*The authors are grateful to two referees and participants at seminars at York University and the Queen's University public economics conference for their comments. Han gratefully acknowledges financial support from the Social Sciences and Humanities Research Council of Canada. 


\begin{tabular}{|llccc|}
\hline \multirow{2}{*}{ Company } & Location & Investment & $\begin{array}{c}\text { Government } \\
\text { Aid }\end{array}$ & $\begin{array}{c}\text { Annual } \\
\text { Output }\end{array}$ \\
& & & & \\
Honda & Lincoln, AL & 825 & 248 & 270 \\
Hyundai & Montgomery, AL & 1000 & 252 & 300 \\
Nissan & Canton, MS & 1400 & 360 & 400 \\
Toyota & Princeton, IN & 1900 & 117 & 400 \\
Toyota & San Antonio, TX & 800 & 133 & 150 \\
Toyota & Woodstock, ON & 625 & 100 & 100 \\
\multicolumn{2}{|c|}{ Source: } & The Globe and Mail, Toronto, 1 July 2005. Investment and \\
\multicolumn{2}{c}{ aid are in millions of US dollars; output is in thousands of vehicles. } \\
\hline
\end{tabular}

Table 1: Assembly Plants Built by Asian Auto Makers in North America since 1998

tax rates generally vary across regions, and that the variation in tax rates leads to an inefficient allocation of capital: the low tax regions use too much capital and the high tax regions use too little (see Wilson 1999). A limitation of this literature is that it assumes that a government can only attract capital by reducing the rate at which it taxes profits. In reality governments attach so much importance to new capital investment that they will often make substantial financial concessions to get it. Table 1 shows the concessions recently given to Asian auto makers building assembly plants in North America. These concessions have been as high as $30 \%$ of the new investment.

If competition among governments is to be properly understood, the focus must be on the overall financial package and the way in which that package varies from firm to firm. A model of this sort is described here. A key element of the model is that capital is embodied in heterogeneous firms. Each firm is mobile, and each firm's productivity varies from region to region. The firms differ in the way that their productivity varies across regions. Each firm receives an offer from the government of every region, and locates in the region in which its after-tax profits would be highest. The government uses its tax revenue to provide a public good to the region's citizens.

Casual observation shows that governments are prepared to negotiate with some firms but not with others, so this model is an abstraction. The standard tax competition model, in which no-one gets a special deal, is also an abstraction. Our view is that these two models constitute polar cases in 
the study of tax competition. Reality lies somewhere between them, but only one of the two poles has been carefully studied. Our hope is that models like this one will ultimately lead to a more balanced view of tax competition.

Our basic model assumes that each government can levy a tax on the profits of firms located within its jurisdiction, and that the government can also levy a lump-sum tax on the incomes of the citizenry. Under these assumptions, the standard tax competition model predicts optimal public goods provision but misallocation of capital. This finding was first presented by Hamada (1966). Hamada's model has been expanded in many different ways, but its core result has remained largely unchanged. The bargaining model, by contrast, predicts both optimal public goods provision and optimal allocation of capital. The resource misallocation that has been the focus of the tax competition literature is simply not there.

Since the existence of such a broadly based lump-sum tax might be viewed with some scepticism, we consider two alternative assumptions. The first is that the lump-sum tax strikes only wages. Capital is again correctly allocated, but optimal provision of the public good is no longer guaranteed. Public goods are optimally provided if the constraint on lump-sum taxation is not binding, and they are underprovided if it is binding. The second is Wilson's (1999) assumption that the profits tax is the only tax. ${ }^{1}$ Wilson shows that, under this assumption, the standard tax competition model predicts both underprovision of the public good and misallocation of capital. The bargaining model is more agnostic. There is underprovision and capital misallocation if the typical firm's gross profits would not fall greatly if it moved from its best location to its second best location, and there is optimal provision and optimal capital allocation if this move would cause the typical firm's gross profits to fall dramatically.

An important feature of these results is that they are derived from a general equilibrium model, and hence can be directly compared to those of the standard fixed-rate model of tax competition. A number of earlier papers have offered explanations of the tax breaks given to mobile firms, but these papers have described the negotiations between a single firm and one or two governments. Doyle and van Wijnbergen (1994) examine the intertemporal structure of a firm's tax payments. They note that a mobile firm has greater

\footnotetext{
${ }^{1}$ Our assumption is actually slightly different from Wilson's, in that we assume that a government that raises too much revenue through the profits tax can return the excess revenue to the citizens through a negative lump-sum tax. Wilson requires an exact match between revenue and public goods expenditure.
} 
bargaining power than a firm that has already incurred the sunk costs associated with locating in a particular region. They argue that mobile firms will use their extra bargaining power to extract concessions. Bond and Samuelson (1986) present an alternative explanation of the same phenomenon: a region can offer a tax holiday to a mobile firm to signal that firms that locate there experience high productivity. The firm will willingly pay higher tax rates in later periods because it is very productive, and these high tax rates allow the government to recover the cost of the initial tax holiday. A low-productivity region could not offer the same incentive: firms that located there would relocate when they found that they had low productivity, so the region would be unable to recover the cost of the tax holiday. King, McAfee and Welling (1993) allow the firm to negotiate simultaneously with two governments, and add a stochastic element to the regional productivities. Black and Hoyt (1989) take an altogether different approach, arguing that subsidies to mobile firms can undo the distortionary effects of average cost pricing of publicly provided services.

Section 2 of this paper sets out an economy in which firms earn locational rents. Section 3 describes the Pareto optimal allocations. Section 4 describes the bargaining model, and derives the major result of the paper: there is no misallocation of capital when governments bargain with firms. Section 5 examines the role of the lump-sum tax, and section 6 contains brief conclusions.

\section{Preliminaries}

The economy consists of $I$ regions and a continuum of firms, each of which operates one unit of capital. The regions are identified by the elements of the set $\mathcal{I} \equiv\{1, \ldots, I\}$. A firm is characterized by its ownership structure and by its productivity in the various regions. A firm's ownership structure is represented by the vector $\gamma \equiv\left(\gamma_{1}, \cdots, \gamma_{I}\right)$, where $\gamma_{i}$ is the fraction of the firm

owned by residents of region $i$. The set of all possible ownership structures is

$$
\Gamma=\left\{\gamma \in[0,1]^{I}: \sum_{i=1}^{I} \gamma_{i}=1\right\}
$$

A firm's productivity in region $i$ is governed by the parameter $\theta_{i} \in \mathbb{R}_{+}$, and the firm's productivity in each of the regions is described by the vector $\theta \equiv\left(\theta_{1}, \cdots, \theta_{I}\right)$. The set of all possible productivity vectors is $\Theta \subset \mathbb{R}_{+}^{I}$. The 
distribution of firms is represented by a $\sigma$-finite measure space $(\Theta \times \Gamma, \mathcal{B}, P)$. Here, $\Theta \times \Gamma$ is the sample space of firms, $\mathcal{B}$ is a $\sigma$-algebra over the sample space, and $P(X)$ denotes the measure of firms in any set $X$ contained in $\mathcal{B}$. It is assumed that $\Theta$ is compact and that $P$ is continuously differentiable.

Each firm locates and produces in one of the regions, or in none of them. The firm's output when it locates in region $i$, denoted $y_{i}$, is determined by $\theta_{i}$ and by $n_{i}$, the quantity of labour employed by the firm:

$$
y_{i}=F\left(\theta_{i}, n_{i}\right)
$$

The production function $F$ is assumed to be concave, strictly increasing and twice continuously differentiable. Furthermore, it displays constant returns to scale and satisfies the Inada conditions. The assumption of constant returns to scale implies that region $i$ 's output can also be written as

$$
y_{i}=\theta_{i} f\left(\frac{n_{i}}{\theta_{i}}\right)
$$

where $f$ is strictly increasing, strictly concave, twice continuously differentiable, and satisfies the Inada conditions.

The total quantity of labour available in region $i$ is fixed and equal to $N_{i}$. Let $L_{i} \subset \Theta \times \Gamma$ be the set of firms that locate in region $i$, and let the distribution of firms across the economy be $L \equiv\left\{L_{1}, \cdots, L_{I}\right\}$. Let the mapping $n: \Theta \times \Gamma \rightarrow \mathbb{R}_{+}$describe the quantity of labour employed by firms of each type.

The residents of each region consume two goods, a private good and a public good. One unit of output can be transformed into one unit of either good. Let $c_{i} \in \mathbb{R}_{+}$be the aggregate quantity of the private good in region $i$, and let $g_{i} \in \mathbb{R}_{+}$be the aggregate quantity of the public good. The social preferences of region $i$ are represented by a social welfare function $s_{i}$, which is assumed to be concave, strictly increasing, and twice continuously differentiable in $\left(c_{i}, g_{i}\right)$. It is also assumed to satisfy the Inada conditions. Let the vectors $c \equiv\left(c_{1}, \cdots, c_{I}\right)$ and $g \equiv\left(g_{1}, \cdots, g_{I}\right)$ describe the aggregate quantities of the private and public goods in the economy as a whole.

An allocation is a list $(L, c, g, n)$. An allocation is feasible if

F1. The sets in $L$ are disjoint, and $\cup_{i=1}^{I} L_{i} \subseteq \Theta \times \Gamma$

F2. The mapping $n$ satisfies the condition

$$
\int_{L_{i}} n d P=N_{i}
$$


for each $i$.

F3. The vectors $c$ and $g$ satisfy the condition

$$
\sum_{i=1}^{I} c_{i}+\sum_{i=1}^{I} g_{i}=\sum_{i=1}^{I} \int_{L_{i}} F\left(\theta_{i}, n\right) d P
$$

Note that this definition of feasibility allows goods produced in one region to be used to increase the aggregate consumption of another region.

Allocations can differ in ways that do not lead to differences in aggregates or in social welfare. The following concepts will be used to identify allocations that differ only in inconsequential ways.

Definition 1 Any two sets $B$ and $B^{\prime}$ in $\mathcal{B}$ are measurably identical if

$$
P\left(\left(B \cup B^{\prime}\right)-\left(B \cap B^{\prime}\right)\right)=0
$$

Definition 2 Any two mappings $\phi: \Theta \times \Gamma \rightarrow \mathbb{R}_{+}$and $\varphi: \Theta \times \Gamma \rightarrow \mathbb{R}_{+}$are measurably identical if

$$
P\{(\theta, \gamma) \in \Theta \times \Gamma: \phi(\theta, \gamma) \neq \varphi(\theta, \gamma)\}=0
$$

Two sets are measurably identical if one can be obtained from the other by adding and/or subtracting a set of measure zero, and two mappings are

measurably identical if their differences are confined to a part of the domain that is measure zero.

\section{Pareto Optimal Allocations}

A feasible allocation $(L, c, g, n)$ is Pareto optimal if there does not exist an alternative feasible allocation $\left(L^{\prime}, c^{\prime}, g^{\prime}, n^{\prime}\right)$ such that $s_{i}\left(c_{i}^{\prime}, g_{i}^{\prime}\right)$ is at least as great as $s_{i}\left(c_{i}, g_{i}\right)$ for all $i$ and $s_{i}\left(c_{i}^{\prime}, g_{i}^{\prime}\right)$ is greater than $s_{i}\left(c_{i}, g_{i}\right)$ for some $i$.

The nature of the Pareto optimal allocations is determined in two steps. Condition F3 and the monotonicity of the social welfare functions imply that any Pareto optimal allocation maximizes the total output of the economy. Since total output is entirely determined by $L$ and $n$, the first step is to find the conditions under which $(L, n)$ maximizes total output. The second step is to find the restrictions that Pareto optimality places on the allocation of output $(c, g)$. 
The relationship between a firm's output and its productivity is given by the increasing function

$$
r\left(\frac{n_{i}}{\theta_{i}}\right) \equiv \frac{\partial F\left(\theta_{i}, n_{i}\right)}{\partial \theta_{i}}=f\left(\frac{n_{i}}{\theta_{i}}\right)-f^{\prime}\left(\frac{n_{i}}{\theta_{i}}\right) \frac{n_{i}}{\theta_{i}}
$$

Multiplying both sides of the identity by $\theta_{i}$ and rearranging gives the identity

$$
y_{i}=\theta_{i} r\left(\frac{n_{i}}{\theta_{i}}\right)+f^{\prime}\left(\frac{n_{i}}{\theta_{i}}\right) n_{i}
$$

This identity breaks the firm's output into two components. The first component is capital's contribution to output (there is one unit of capital and its contribution to output depends upon its productivity), and the second is labour's contribution to output (note that $f^{\prime}$ is the marginal product of labour). The following lemma shows that total output is maximized when each firm locates in the region in which capital's contribution to output is maximized. The proof of this result is contained in the appendix, as are the proofs of all subsequent results.

Lemma 1 Let $\left(L^{*}, n^{*}\right)$ satisfy the conditions:

a. $\cup_{i=1}^{I} L_{i}^{*}=\Theta \times \Gamma$

b. For all $(\theta, \gamma) \in L_{i}^{*}$ and each $i \in \mathcal{I}$,

$$
n^{*}(\theta, \gamma)=\theta_{i} \mu_{i}^{*}
$$

where

$$
\mu_{i}^{*} \equiv \frac{N_{i}}{\int_{L_{i}^{*}} \theta_{i} d P}
$$

c. For each $(\theta, \gamma)$ contained in $\Theta \times \Gamma,(\theta, \gamma) \in L_{i}^{*}$ only if

$$
\theta_{i} r\left(\mu_{i}^{*}\right)=\max _{j \in \mathcal{I}}\left\{\theta_{j} r\left(\mu_{j}^{*}\right)\right\}
$$

An arbitrary tie-breaking rule determines the placement of $(\theta, \gamma)$ if the product $\theta_{j} r\left(\mu_{j}^{*}\right)$ attains its maximum in more than one region $j$.

Then: 
1. Under any given tie-breaking rule, $\left(L^{*}, n^{*}\right)$ exists and is unique. Each $L_{i}^{*}$ is non-empty.

2. Total output is maximized if and only if $(L, n)$ is measurably identical to $\left(L^{*}, n^{*}\right)$.

The first condition simply states that every firm must locate somewhere. The second requires the ratio $n_{i} / \theta_{i}$ to be the same for every firm that locates in region $i$. Since each firm's marginal product of labour is determined by this ratio, this condition ensures that the marginal product of labour is equalized across the firms that locate in region $i$. The third condition states that each firm locates in the region in which capital's contribution to output is maximized. It is not surprising that output maximization requires the first and second conditions, but why does it require the third condition? Suppose that a small but positive measure of firms is moved from region $h$ to region $j$. The firms entering region $j$ are provided with labour by shifting labour away from the firms that were already in that region, so labour's contribution to the output of the new firms is exactly offset by the fall in labour's contribution to the output of the existing firms. Likewise, the departure of the firms leaving region $h$ means that more labour is available to the remaining firms, so that the loss of labour's contribution to the output of the departing firms is offset by an increase in labour's contribution to the output of the firms that remain. The change in total output is therefore equal to the change in capital's contribution to the output of the firms that move.

Let $Y^{*}$ be the maximal value of total output, and let $R \equiv\left(R_{1}, \ldots, R_{I}\right)$ represent the way in which total output is distributed across regions. The definition of a feasible allocation assumed that goods produced in one region could be allocated to any region, so the only restriction on $R$ is that

$$
\sum_{i=1}^{I} R_{i}=Y^{*}
$$

A unit of the produced good can be converted into one unit of either good, so

$$
c_{i}+g_{i}=R_{i} \quad \text { for all } i \in \mathcal{I}
$$

Given $R_{i}$, the optimal choice of $\left(c_{i}, g_{i}\right)$ maximizes $s_{i}\left(c_{i}, g_{i}\right)$ subject to $(2)$ and non-negativity constraints on $c_{i}$ and $g_{i}$. The restrictions on $s_{i}$ imply that the non-negativity constraints do not bind for any positive $R_{i}$.

Theorem 1 fully characterizes a Pareto optimal allocation. 
Theorem 1 A feasible allocation $(L, n, c, g)$ is Pareto optimal if and only if

P1. $(L, n)$ is measurably identical to $\left(L^{*}, n^{*}\right)$.

P2. $\left(c_{i}, g_{i}\right)$ satisfies the condition

$$
\frac{\partial s_{i}\left(c_{i}, g_{i}\right)}{\partial g_{i}}=\frac{\partial s_{i}\left(c_{i}, g_{i}\right)}{\partial c_{i}}
$$

for each $i \in \mathcal{I}$.

The location of the firms and the allocation of labour across firms are measurably identical in every Pareto optimal allocation, but the division of resources between the regions varies substantially across the Pareto optimal allocations. Indeed, every division of resources that satisfies (1) is part of some Pareto optimal allocation.

\section{Bargaining over Tax Rates}

A government sets the rate at which it taxes the profits of all firms, but it can also offer tax holidays, infrastructure investment, loan guarantees or other financial incentives to particular firms. A firm evaluates an offer by calculating the implied maximal after-tax profits, that is, the after-tax profits earned when the profit-maximizing quantity of labour is employed. To simplify the analysis in this section, it is assumed that (a) the financial concessions, like the profits tax itself, do not distort the hiring decision, and (b) the offer made by each government to a particular firm specifies the maximal after-tax profits that the firm would earn in the region. The offers made by the government of region $i$ to firms of all types are represented by the mapping $\pi_{i}: \Theta \times \Gamma \rightarrow \mathbb{R}$, and the offers made by all governments are given by $\pi \equiv\left(\pi_{1}, \ldots, \pi_{I}\right)$.

An equilibrium consists of a collection $(\pi, c, g, w, L, n)$. It unfolds in two stages:

1. The government of each region $i$, taking the offers of the other governments as given, chooses $\pi_{i}$ such that region $i$ 's social welfare cannot be raised by changing the maximal after-tax profits offered to the firms in any set of positive measure. Each government anticipates the impact of its policies on wage rates and on the firms' location and employment decisions. 
2. Firms of each type $(\theta, \gamma)$ locate in some region $j$ if no other region offers maximal after-tax profits greater than $\pi_{j}(\theta, \gamma)$. A firm that locates in regio $i$ observes the market-clearing wage $w_{i}$ and employs the profit maximizing quantity of labour. The government of each region $i$ chooses $\left(c_{i}, g_{i}\right)$ and its own lump-sum tax to maximize the region's social welfare function.

In stage 2 each firm locates in the region in which its maximal after-tax profits are highest. If it locates in region $i$, it employs the quantity of labour that satisfies the condition

$$
f^{\prime}\left(\frac{n_{i}}{\theta_{i}}\right)=w_{i}
$$

The ratio $n_{i} / \theta_{i}$ is the same for every firm in the region, and since the wage rate clears the regional labour market, this ratio must be equal to

$$
\mu_{i} \equiv \frac{N_{i}}{\int_{L_{i}} \theta_{i} d P}
$$

The gross profits of a firm in this region are equal to $\theta_{i} r\left(\mu_{i}\right){ }^{2}$

The resources available to region $i$, denoted $R_{i}$, are equal to domestic output, less the after-tax profits earned within the region, plus the citizens' share of the after-tax profits of all firms.

$$
R_{i}=f\left(\mu_{i}\right) \int_{L_{i}} \theta_{i} d P-\int_{L_{i}} \pi_{i} d P+\sum_{j=1}^{I}\left(\int_{L_{j}} \gamma_{i} \pi_{j} d P\right)
$$

Each region will use the lump-sum tax to ensure the optimal division of its resources between the private and public goods, so it chooses its offers to maximize the region's resources.

Lemma 2 Let $\pi$ be given, and assume that each firm chooses its location to maximize its after-tax profits. Region $i$ cannot increase its resources $R_{i}$ by changing its offers to the firms in any set of positive measure if and only if these conditions hold:

\footnotetext{
${ }^{2}$ Let $m$ be a subset of the firms located in region $i$, and let $z_{m}$ be the be integral of their productivities. Then $z_{m} f\left(\mu_{i}\right)$ is their total output, $z_{m} \mu_{i}$ is total employment at these firms, and $f^{\prime}\left(\mu_{i}\right)$ is the wage rate.
} 
E1. Almost every firm that locates in region $i$ has a matching offer from some other region.

E2. Almost every firm that locates in region $i$ satisfies

$$
\theta_{i} r\left(\mu_{i}\right) \geq \pi_{i}(\theta, \gamma)
$$

E3. Almost every firm that locates in any other region $j$ satisfies

$$
\theta_{i} r\left(\mu_{i}\right) \leq \pi_{j}(\theta, \gamma)
$$

Consider a firm that locates in some region $i$. Condition 2 implies that the firm's gross profits in that region are at least as great as its after-tax profits in the same region. Condition 3 implies that its after-tax profits in region $i$ are at least as great as its gross profits in any other region. It follows that a firm locates in region $i$ almost always attains its greatest gross profits in that region, and that its after-tax profits almost always lie between its second highest and highest gross profits.

The effective tax rate for a firm of type $(\theta, \gamma)$ in region $i$ is

$$
t_{i}(\theta, \gamma) \equiv \frac{\theta_{i} r\left(\mu_{i}\right)-\pi_{i}(\theta, \gamma)}{\theta_{i} r\left(\mu_{i}\right)}
$$

The range of possible effective tax rates is very wide. A firm's effective tax rate is 0 if its second highest gross profits are equal to its highest gross profits. It can be as high as 1 if the firm's second highest gross profits are equal to zero - that is, if the firm is effectively immobile. The effective tax rate is never negative, implying that any concessions received by a firm are subsequently taxed back.

In a fixed-rate model with homogeneous capital, the signs of the regions' tax rates are determined by Hamada's (1966) terms of trade effect. If there are only two regions, for example, the region that is a net recipient of aftertax profits will choose a negative tax rate. Its subsidization of capital will drive up the economy-wide after-tax return to capital, which is beneficial to a region that receives more profits than it pays out. The other region will do the opposite, taxing profits to drive down the economy-wide after-tax return to capital. Burbidge, Cuff and Leach (2006) show that the terms of trade effect survives, albeit in a weaker form, when the production technology described in section 2 is employed in a fixed-rate model of tax competition. 
This technology creates locational rents for the firms. Since governments can capture locational rents that would otherwise accrue to foreigners by levying positive profits taxes, the presence of locational rents puts upward pressure on the profit tax. In this model the terms of trade effect determines the relative sizes of the tax rates rather than their signs. By contrast, nothing resembling the terms of trade effect arises in the bargaining model.

The terms of trade effect causes the distribution of ownership to play a critical role in determining the tax rates in fixed rate models. There is no terms of trade effect in the bargaining model, so the distribution of ownership has no impact on the effective tax rates.

Since almost every firm locates in the region in which its gross profits are greatest, it is not surprising that an equilibrium allocation is Pareto optimal.

Theorem 2 If the governments can tax the incomes of domestic residents in a lump-sum fashion, an equilibrium exists. The equilibrium allocations are measurably identical and Pareto optimal, and the market-clearing wages are identical across equilibria.

The bargaining model shows that tax competition does not necessarily lead to a misallocation of resources. The lump-sum tax plays a significant role in generating this result, but the next section shows that an efficient allocation of resources can arise without one.

\section{The Lump-Sum Tax}

It has been assumed that the government is able to levy lump-sum taxes on wages and on the domestic residents' share of the after-tax profits of all firms. The role played by the lump-sum tax is explored here by eliminating the lump-sum tax in a stepwise fashion. The first step limits the scope of the lump-sum tax to wages, and the second eliminates the lump-sum tax entirely. ${ }^{3}$ These changes have quite different (and perhaps surprising) effects on the equilibrium.

There is no change in the equilibrium concept, but there is an additional restriction on each government's behaviour. If the lump-sum tax has limited scope, some of the region's resources cannot be appropriated by the government and therefore cannot be allocated to the provision of the public good.

\footnotetext{
${ }^{3}$ The assumption that a government can transfer excess revenue back to the citizens in a lump-sum fashion is retained throughout.
} 
Let $R_{i}^{g}$ be the part of region $i$ 's resources that can be allocated to the public good, and let $R_{i}^{c}$ be the part that cannot be allocated to it. Region $i$ 's government solves the optimization problem

$$
\begin{aligned}
\max _{c_{i}, g_{i}} S_{i} & =s_{i}\left(c_{i}, g_{i}\right) \\
\text { s.t. } c_{i}+g_{i} & =R_{i}^{c}+R_{i}^{g} \\
g_{i} & \leq R_{i}^{g}
\end{aligned}
$$

Let the solution to this problem be the functions $c_{i}\left(R_{i}^{c}, R_{i}^{g}\right)$ and $g_{i}\left(R_{i}^{c}, R_{i}^{g}\right)$, and let the associated maximum value function be $S_{i}\left(R_{i}^{c}, R_{i}^{g}\right)$.

\subsection{Only Wages are Subject to Lump-Sum Taxation}

Under this assumption, the government can finance the public good from either the wage tax or the profits tax, implying

$$
\begin{gathered}
R_{i}^{g}=f\left(\mu_{i}\right) \int_{L_{i}} \theta_{i} d p-\int_{L_{i}} \pi_{i}(\theta, \gamma) d P \\
R_{i}^{c}=\sum_{j=1}^{I}\left(\int_{L_{j}} \gamma_{i} \pi_{j}(\theta, \gamma) d P\right)
\end{gathered}
$$

Restricting the governments' choices in this fashion does not alter the offers that the governments make and does not alter the equilibrium $(L, n)$.

Lemma 3 Assume that governments can tax only the wages of domestic residents in a lump-sum fashion, and that region $i$ will choose this tax to maximize social welfare $s_{i}$. Let $\pi$ be given, and assume that each firm chooses its location to maximize its after-tax profits. Region $i$ cannot increase $s_{i}$ by changing its offers to the firms in any set of positive measure if and only if conditions E1-E3 hold.

As before, these conditions imply that a firm almost always locates in the region in which its gross profits are highest, and that its after-tax profits almost always lie between its second highest and highest gross profits.

The government of region $i$ is willing to offer the same after-tax profits when the inequality constraint is binding - when government revenue has a high social value - as when it is not binding. A binding constraint implies 
that $R_{i}^{g}$ is low relative to $R_{i}^{c}$. Since $R_{i}^{g}$ is derived entirely from firms that locate within the region, and since any reduction in the after-tax profits offered to a firm will induce the firm to locate elsewhere, the government is unwilling to moderate its offer to any firm.

Theorem 3 Assume that only the wages of domestic residents can be taxed in a lump-sum fashion. Then an equilibrium exists, and the market-clearing wages are the same in every equilibrium. Also,

1. $(L, n)$ is measurably identical to $\left(L^{*}, n^{*}\right)$.

2. An equilibrium that gives rise to a Pareto optimal allocation exists under some specifications of the model.

Since the offers that are made to each firm do not change when the scope of the lump-sum tax is restricted, neither does the actual location of the firm. Total output is maximized even under the more restrictive tax assumption. However, there is no assurance that each government will raise enough revenue to provide the efficient quantity of public goods.

These results are the reverse of a common representation of Hamada's (1966) tax competition model. In that model, the existence of a lump-sum wage tax is commonly assumed to ensure the optimal provision of public goods, while the terms of trade effect causes capital to be misallocated across regions. Our findings are that firms (which embody the available capital) are correctly allocated across regions, but that the optimal provision of public goods is not assured.

\subsection{No Lump-Sum Tax}

Wilson (1999) studies a fixed-rate tax competition model in which the profits tax is the only available tax. He finds that, if the regions are not identical, the equilibrium tax rates distort both the division of capital between regions and the division of a region's resources between the private and public goods. If the regions are identical, each region will underprovide the public good. An analogous equilibrium is described here.

The resources of government $i$ are

$$
R_{i}^{c}=\left(f\left(\mu_{i}\right)-r\left(\mu_{i}\right)\right) \int_{L_{i}} \theta_{i} d p+\sum_{j=1}^{I}\left(\int_{L_{j}} \gamma_{i} \pi_{j}(\theta, \gamma) d P\right)
$$




$$
R_{i}^{g}=r\left(\mu_{i}\right) \int_{L_{i}} \theta_{i} d p-\int_{L_{i}} \pi_{i}(\theta, \gamma) d P
$$

Equilibrium after-tax profits are now influenced by the relative scarcities of the two types of resources. Their relative scarcity is summarized by the marginal rate of substitution

$$
M R S_{i} \equiv \frac{\partial S_{i}}{\partial R_{i}^{g}} \div \frac{\partial S_{i}}{\partial R_{i}^{c}}
$$

which measures the value of a unit of $R_{i}^{g}$ in terms of $R_{i}^{c}$, or equivalently, a unit of public goods in terms of private goods. The marginal rate of substitution is 1 if the inequality constraint in the government's maximization problem is not binding, and it is greater than 1 if it is binding. After-tax profits are also influenced by the elasticity

$$
\varepsilon\left(\mu_{i}\right) \equiv \frac{\mu_{i} r^{\prime}\left(\mu_{i}\right)}{r\left(\mu_{i}\right)}
$$

The following lemma describes the location of the firms and their after-tax profits in any equilibrium.

Lemma 4 Assume that the profits tax is the only available tax. Consider a firm of a type contained in $L_{i}$. Define the variables

$$
\rho\left(\mu_{j}, M R S_{j}\right) \equiv r\left(\mu_{j}\right)\left[\frac{\varepsilon\left(\mu_{j}\right)}{M R S_{j}}+\left(1-\varepsilon\left(\mu_{j}\right)\right)\right] \quad \text { for all } j \in \mathcal{I}
$$

Then, in any equilibrium,

$$
\theta_{i} \rho\left(\mu_{i}, M R S_{i}\right)=\max _{j \in \mathcal{I}}\left\{\theta_{j} \rho\left(\mu_{j}, M R S_{j}\right)\right\}
$$

Furthermore, the firm's after-tax profits satisfy the inequality

$$
\max _{j \neq i}\left\{\theta_{j} \rho\left(\mu_{j}, M R S_{j}\right)\right\} \leq \pi_{i}(\theta, \gamma) \leq \theta_{i} \rho\left(\mu_{i}, M R S_{i}\right)
$$

An additional firm brings $\theta_{i} r\left(\mu_{i}\right)$ additional units of resources to region $i$. A fraction $\varepsilon\left(\mu_{i}\right)$ accrues to the region in the form of wages and the remainder accrues as pre-tax profits. Each unit of untaxable wages is worth one unit of private goods or $1 / M R S_{i}$ units of public goods, and each unit of taxable gross profits is worth one unit of public goods, so $\theta_{i} \rho\left(\mu_{i}, M R S_{i}\right)$ represents 
the value of these additional resources measured in units of public goods. The cost of attracting a firm is $\pi_{i}(\theta, \gamma)$ units of after-tax profits, each unit of which has an opportunity cost of one unit of public goods. Thus, $\theta_{i} \rho\left(\mu_{i}, M R S_{i}\right)$ and $\pi_{i}(\theta, \gamma)$ represent the benefit and cost of an additional firm, both measured in units of public goods.

If the provision of public goods in some region $i$ is not constrained by a lack of tax revenue - if $M R S_{i}$ is equal to one - the lowest effective tax rate that a firm might pay is zero. However, a region that is constrained by its tax revenue will require every firm to pay taxes. Specifically, the lowest effective tax rate is

$$
\underline{t}=\varepsilon\left(\mu_{i}\right)\left(1-\frac{1}{M R S_{i}}\right)
$$

This rate rises from zero as $M R S_{i}$ rises from one. Likewise, the firm's maximum effective tax rate rises with the marginal rate of substitution in the region that places the next highest value on the firm.

The existence and uniqueness of equilibrium has not been proved for this economy. The remainder of this section explores the properties of equilibrium by describing a symmetric economy in which the production function is

$$
y_{i}=\theta_{i}^{\alpha} n_{i}^{1-\alpha}
$$

so that $\varepsilon$ is constant. The following lemma shows that, for these economies, there is a link between the two elements of Pareto optimality, namely output maximization and efficient allocation.

Lemma 5 Assume that the profits tax in the only tax and that the production function is (3). In any equilibrium, output is maximized if and only if every region has the same marginal rate of substitution.

Lemma 5 suggests that almost all equilibria fall into one of two categories: either the allocation is Pareto optimal, or total output is not maximized and public goods are underprovided. The only exceptions are "knife-edge" equilibria in which every region underprovides the public good but has the same marginal rate of substitution, so that total output is maximized. The symmetric equilibrium will sometimes be of this unusual type.

Imagine an economy with two regions, each of which has the production function (3). There is one unit of labour in each region. The productivity profile of a firm takes one of two forms: it is either

$$
\left(\theta_{1}, \theta_{2}\right)=(\widehat{\theta}, \lambda \widehat{\theta})
$$


or

$$
\left(\theta_{1}, \theta_{2}\right)=(\lambda \widehat{\theta}, \widehat{\theta})
$$

Here, $\lambda$ is a positive fraction and $\widehat{\theta}$ is an element of some bounded interval of positive real numbers, denoted $J$. For any subset $X$ of $J$, the fraction of all firms for which $\widehat{\theta}$ is contained in $X$ is given by the measure $P(X)$. Half of these firms are more productive in region 1 and half are more productive in region 2. It is also assumed that

$$
\int_{J} \widehat{\theta} d P=1
$$

which implies that the measure of all firms is 2 . The fraction of a firm of type $(\widehat{\theta}, \lambda \widehat{\theta})$ owned by the residents of region 1 is equal to the fraction of a firm of type $(\lambda \widehat{\theta}, \widehat{\theta})$ owned by the residents of region 2 , and is denoted $\gamma(\widehat{\theta})$. This assumption implies that half of all after-tax profits accrue to each region. It is assumed that each firm pays the largest tax consistent with equilibrium.

One candidate for the equilibrium allocation is the output-maximizing allocation. Under this allocation, each firm goes to the region in which its productivity factor is greatest. The available labour in each region $i$ is distributed across the firms so that the ratio $n_{i} / \widehat{\theta}$ is the same for all firms. Then, in each region $i$,

$$
\begin{gathered}
Z_{i}=\mu_{i}=Y_{i}=1 \\
R_{i}^{c}=1-(1-\lambda) \alpha \\
R_{i}^{g}=(1-\lambda) \alpha
\end{gathered}
$$

The offer made to each firm is equal to its gross profits in the low-productivity region. That is, firms of type $(\widehat{\theta}, \lambda \widehat{\theta})$ or type $(\lambda \widehat{\theta}, \widehat{\theta})$ are offered after-tax profits of $\alpha \lambda \widehat{\theta}$. This allocation is an equilibrium allocation if neither government can increase social welfare in its region by changing its offers to a measurable set of firms. This condition is satisfied; see the appendix for details.

Although the symmetric equilibrium always maximizes output, it might or might not efficiently allocate output. Under any increasing and strictly concave social welfare function, public goods will be optimally provided if $R_{i}^{g}$ is a sufficiently large part of total output, or equivalently, if $(1-\lambda) \alpha$ is sufficiently large. A high value of $\alpha$ implies that profits - the only part of output that is taxable - constitute a large fraction of output. A small value of $\lambda$ implies that every firm's second-best location is much worse than its best location, so that it is willing to accept high taxes in the best location. 
The fixed-rate tax competition model does not generate a Pareto optimal allocation, but the bargaining model will sometimes to do so. This difference arises in part because the firms in the bargaining model are less mobile than the firms in the fixed-rate model. Capital in the fixed-rate model is truly mobile, in the sense that it can move to any region and is equally productive in every region. Each firm in the bargaining model is mobile in the sense that it can locate in any region, but it might be immobile in the sense that it cannot move between regions without a significant loss of productivity. The extent of these productivity losses largely explains the difference in results. If each firm's second best option is almost as good as its best option, the government's revenue is likely to be so small that public goods will be underprovided, and underprovision almost always leads to capital misallocation. However, if each firm's second best option is much worse than its best option, each government will be able to collect significant tax revenue. If each region's preferences for the public good are not very strong, these revenues might be large enough to allow each region to provide the optimal quantity of public goods. There is no capital misallocation if public goods are optimally provided in every region. Thus, relatively high mobility (in the sense of movement without significant loss) gives rise to allocations that are not Pareto optimal, as in Wilson (1999), while relatively low mobility gives rise to Pareto optimal allocations.

\section{Conclusions}

The standard model of tax competition assumes that each government taxes every firm's profits at the same rate. Regional differences in productivity or in endowments lead to an equilibrium in which there is a range of tax rates. Resources are misallocated, with the low tax regions using too much capital and the high tax regions using too little. By contrast, the model set out above assumes that the governments negotiate separately with every firm. The predictions of the model depend upon the nature of the supplementary taxes in the economy. If all of income is subject to a lump-sum tax, a Pareto optimal allocation is reached; if only wages are subject to a lump-sum tax, there can be underprovision of the public good but capital is again optimally allocated. A Pareto optimal allocation might even occur if governments cannot use a lump-sum tax to raise revenue. 


\section{Appendix}

Let $k \equiv\left(k_{1}, \cdots, k_{I}\right)$ be a vector of non-negative real numbers. For each $k$, let $L(k) \equiv\left\{L_{1}(k), \cdots, L_{I}(k)\right\}$ be the unique collection of disjoint sets that satisfies these conditions:

C1. $\cup_{i=1}^{I} L_{i}(k)=\Theta \times \Gamma$.

C2. For each $i \in \mathcal{I},(\theta, \gamma) \in L_{i}(k)$ implies that $k_{i} \theta_{i}=\max \left[k_{1} \theta_{1}, \cdots, k_{I} \theta_{I}\right]$. An arbitrary "tie-breaking" rule determines the placement of firms for which the product $k_{i} \theta_{i}$ reaches its maximum in more than one region.

Define the functions

$$
Z_{i}(k) \equiv \int_{L_{i}(k)} \theta_{i} d P \quad \text { for all } i \in \mathcal{I}
$$

and let $k^{\circ}$ be the solution to the equation system

$$
k_{i}=\eta_{i} \times r\left(\frac{N_{i}}{Z_{i}(k)}\right) \quad \text { for all } i \in \mathcal{I}
$$

Here, each $\eta_{i}$ is a positive constant. Then $k^{\circ}$ has these properties.

FP1. The vector $k^{\circ}$ exists and is unique, and $k_{i}^{\circ}$ and $Z_{i}\left(k^{\circ}\right)$ are strictly positive for each $i \in \mathcal{I}$.

FP2. An increase in $\eta_{j}$ causes $k_{j}^{\circ}$ and each ratio $k_{j}^{\circ} / k_{i}^{\circ}(i \in \mathcal{I}, i \neq j)$ to rise.

Proof of FP1: Let $k^{\circ}$ be a fixed point of (4), and let $s^{\circ}$ be the vector such that

$$
s_{i}^{\circ}=\frac{k_{i}^{\circ}}{\sum_{l=1}^{I} k_{l}^{\circ}} \quad \text { for all } i \in \mathcal{I}
$$

Since $Z_{i}(k)$ is linearly homogeneous, $s^{\circ}$ is the fixed point of the equation system

$$
s_{i}=\frac{\eta_{i} r\left(\frac{N_{i}}{Z_{i}(s)}\right)}{\sum_{l=1}^{I} \eta_{l} r\left(\frac{N_{l}}{Z_{l}(s)}\right)} \quad \text { for all } i \in \mathcal{I}
$$


By definition, every fixed point of (4) gives rise to a unique fixed point of (5). Also, by the linear homogeneity of $Z_{i}$,

$$
k_{i}^{\circ}=\eta_{i} r\left(\frac{N_{i}}{Z_{i}\left(k^{\circ}\right)}\right)=\eta_{i} r\left(\frac{N_{i}}{Z_{i}\left(s^{\circ}\right)}\right) \quad \text { for all } i \in \mathcal{I}
$$

so that each fixed point of (5) gives rise to a fixed point of (4). Thus, $k^{\circ}$ exists and is unique if $s^{\circ}$ exists and is unique. The existence and uniqueness of $s^{\circ}$ are proved in turn:

1. The difficulty of proving the existence of the fixed point of (5) is that the right-hand side of $(5)$ is not bounded or not defined if some $k_{i}$ is zero. This problem is circumvented by considering the mapping

$$
q_{i}^{\epsilon}(s)=\frac{\eta_{i} r\left(\frac{N_{i}}{Z_{i}(s)+\epsilon}\right)}{\sum_{l=1}^{I} \eta_{l} r\left(\frac{N_{l}}{Z_{l}(s)+\epsilon}\right)} \quad \text { for all } i \in \mathcal{I}
$$

Define the set

$$
\mathbb{S} \equiv\left\{s \in \mathbb{R}_{+}^{I}: \sum_{l=1}^{I} s_{l}=1\right\}
$$

This set is non-empty, compact and convex. For each $\epsilon>0$, the mapping $q^{\epsilon}: \mathbb{S} \rightarrow \mathbb{S}$ is well-defined even when some elements of $s$ are zero. The assumptions on $P$ ensure that $q^{\epsilon}$ is a continuous mapping from $\mathbb{S}$ into $\mathbb{S}$. Taken together, these conditions ensure the existence of a fixed point $s^{\epsilon}=$ $\left(s_{1}^{\epsilon}, \cdots, s_{I}^{\epsilon}\right)$. Furthermore, the construction of the mapping ensures that $s_{i}^{\epsilon}$ is strictly positive for all $i$ and all $\epsilon>0$. Since $s^{\epsilon}$ is a fixed-point of $q^{\epsilon}$, we have

$$
s_{i}^{\epsilon}=\frac{\eta_{i} r\left(\frac{N_{i}}{Z_{i}\left(s^{\epsilon}\right)+\epsilon}\right)}{\sum_{l=1}^{I} \eta_{l} r\left(\frac{N_{l}}{Z_{l}\left(s^{\epsilon}\right)+\epsilon}\right)} \quad \text { for all } i \in \mathcal{I}
$$

Since $0<s_{i}^{\epsilon}<1$ for all $i$ at each $\epsilon$, the positive sequence $\left\{s^{\epsilon}\right\}$ is bounded. Therefore, there exists a subsequence of $\left\{s^{\epsilon}\right\}$ that must converge as $\epsilon \rightarrow 0$. For simplicity, assume that we choose this convergent subsequence right from the start so that $\left\{s^{\epsilon}\right\}$ itself converges to $s^{\circ}$ as $\epsilon \rightarrow 0$.

Now we will show that $0<s_{i}^{\circ}<1$ for all $i \in \mathcal{I}$. Suppose not. Then there exists a non-empty subset $\mathcal{D} \subset \mathcal{I}$ such that $s_{i}^{\circ}=0$ for all $i \in \mathcal{D}$. Then we have $Z_{i}\left(s^{\circ}\right)=0$ for all $i \in \mathcal{D}$ because every firm will be located in some 
region $i^{\prime}$ such that $s_{i^{\prime}}^{\circ}>0$. Furthermore, $Z_{i}\left(s^{\epsilon}\right) \rightarrow Z_{i}\left(s^{\circ}\right)=0$ as $\epsilon \rightarrow 0$. $\sum_{l \in \mathcal{D}} s_{l}^{\epsilon}$ is expressed by

$$
\sum_{l \in \mathcal{D}} s_{l}^{\epsilon}=\frac{\sum_{l \in \mathcal{D}} \eta_{l} r\left(\frac{N_{l}}{Z_{l}\left(s^{\epsilon}\right)+\epsilon}\right)}{\sum_{l \in \mathcal{D}} \eta_{l} r\left(\frac{N_{l}}{Z_{l}\left(s^{\epsilon}\right)+\epsilon}\right)+\sum_{l \notin \mathcal{D}} \eta_{l} r\left(\frac{N_{l}}{Z_{l}\left(s^{\epsilon}\right)+\epsilon}\right)}
$$

Note that $s^{\epsilon}$ is a fixed point of $q^{\epsilon}$, so $Z_{l}\left(s^{\epsilon}\right)+\epsilon$ is bounded and positive for all $l \notin \mathcal{D}$ at any $\epsilon$. This implies that $\left\{\sum_{l \notin \mathcal{D}} \eta_{l} r\left(\frac{N_{l}}{Z_{l}\left(s^{\epsilon}\right)+\epsilon}\right)\right\}$ is a bounded and positive sequence. Furthermore, because $r$ is positive and strictly increasing, there exists a positive constant $z>0$ such that $\left\{\sum_{l \in \mathcal{D}} \eta_{l} r\left(\frac{N_{l}}{Z_{l}\left(s^{\epsilon}\right)+\epsilon}\right)\right\}$ is bounded above $z$. Therefore, we have $\sum_{l \in \mathcal{D}} s_{l}^{\epsilon} \nrightarrow 0$ as $\epsilon \rightarrow 0$. This contradicts $\sum_{l \in \mathcal{D}} s_{l}^{\circ}=0$. It follows that $0<s_{i}^{\circ}<1$ for all $i$. Since $s^{\circ}$ is a fixed point of (5) and $0<s_{i}^{\circ}<1$ for all $i$, we have $Z_{i}\left(s^{\circ}\right)>0$ for all $i$. Therefore, a fixed point $k^{\circ}$ (with $k_{i}^{\circ}>0$ for all $i$ ) of $(4)$ exists and $Z_{i}\left(k^{\circ}\right)=Z_{i}\left(s^{\circ}\right)>0$ for all $i$

2. Assume that $s^{\circ}$ is not a unique fixed point, and let $s^{0}$ and $s^{1}$ be two of the fixed points. Let region $a$ be the region in which the ratio $s_{i}^{0} / s_{i}^{1}$ is lowest. This ratio must be smaller than 1 . (If it were not, every element of $s^{0}$ would be greater than the corresponding element of $s^{1}$. Since every fixed point has the property that $\sum_{i} s_{i}=1$, at least one of the two vectors could not be a fixed point.) Then, for all $\theta \in \Theta$ and all $j \neq a$,

$$
\theta_{j} \frac{s_{j}^{1}}{s_{a}^{1}} \leq \theta_{j} \frac{s_{j}^{0}}{s_{a}^{0}},
$$

Furthermore, the inequality must be strict for some $j$. Since a firm locates in region $a$ if and only if $\theta_{a}>\theta_{j}\left(s_{j} / s_{a}\right)$ for all $j \neq a$, (6) implies that $Z_{a}\left(s^{0}\right)<Z_{a}\left(s^{1}\right)$. Then, using (5),

$$
\frac{s_{a}^{0}}{s_{a}^{1}}=\frac{r\left(\frac{N_{a}}{Z_{a}\left(s^{0}\right)}\right)}{r\left(\frac{N_{a}}{Z_{a}\left(s^{1}\right)}\right)}>1
$$

which contradicts the initial assumption that $s_{a}^{0} / s_{a}^{1}$ is smaller than 1 . Thus, the fixed point $s^{\circ}$ must be unique.

Proof of FP2: This property is proved by demonstrating that any other outcome leads to a contradiction. If $Z_{j}\left(k^{\circ}\right)$ does not rise when $\eta_{j}$ rises, $k_{j}^{\circ}$ must rise to satisfy the $j^{t h}$ equation in the system. However, if $Z_{j}\left(k^{\circ}\right)$ does not 
rise, there must be at least one element $k_{i}^{\circ}$ that rises by a greater proportion than $k_{j}^{\circ}$. Let $k_{h}^{\circ}$ be the element that experiences the greatest proportionate increase. Since $k_{h}^{\circ}$ and $Z_{h}\left(k^{\circ}\right)$ both rise, the $h^{\text {th }}$ equation in the system is not satisfied. Thus, $Z_{j}\left(k^{\circ}\right)$ must rise in response to the increase in $\eta_{j}$. If $k_{j}^{\circ}$ does not rise while $Z_{j}\left(k^{\circ}\right)$ rises, there must be at least one element $k_{i}^{\circ}$ that falls by a greater proportion than $k_{j}^{\circ}$. Let $k_{h}^{\circ}$ be the element that experiences the greatest proportionate decline. Since both $k_{h}^{\circ}$ and $Z_{h}\left(k^{\circ}\right)$ fall, the $h^{\text {th }}$ equation in the system is not satisfied. Thus, the rise in $Z_{j}\left(k^{\circ}\right)$ must be accompanied by an increase in $k_{j}^{\circ}$. Let $k_{h}^{\circ}$ be the element of $k^{\circ}$ that experiences the greatest proportionate increase. If its proportionate increase is at least as great as that of $k_{j}^{\circ}, Z_{h}\left(k^{\circ}\right)$ also rises, so that the $h^{\text {th }}$ equation in the system cannot be satisfied. It follows that the proportionate increase in $k_{j}^{\circ}$ must be greater than the proportionate increase in any other element of $k^{\circ}$.

Proof of Lemma 1: The restrictions that Lemma 1 places upon $L$ imply that $L^{*}$ is equal to $L\left(k^{*}\right)$ where

$$
k_{i}^{*}=r\left(\frac{N_{i}}{\int_{L_{i}^{*}} \theta_{i} d P}\right) \quad \text { for all } i \in \mathcal{I}
$$

Consequently, $k^{*}$ is the fixed point of

$$
k_{i}^{*}=r\left(\frac{N_{i}}{Z_{i}\left(k^{*}\right)}\right) \quad \text { for all } i \in \mathcal{I}
$$

Since this system is simply (4) with $\eta_{i}$ set equal to one, the existence and uniqueness of $k^{*}$ and $L^{*}$ follows immediately from FP1, as does the finding that each $L_{i}^{*}$ is non-empty. The labour allocation $n^{*}$ is entirely determined by $L^{*}$. To prove the second part of Lemma 1, suppose that the location decision $L$ is not measurably identical to $L\left(k^{*}\right)$. Then, under the location rule $L$, there exists a compact set $M_{i}$ of firms in region $i$ such that $P\left(M_{i}\right)>0$ and $k_{j} \theta_{j}>k_{i} \theta_{i}$ for all firms in $M_{i}$. It will be shown that moving a subset of these firms from region $i$ to region $j$ raises total output. Let $\mathcal{M}_{i}$ be the set of all subsets of $M_{i}$, and identify some $(\theta, \gamma) \in M_{i}$. Define a mapping $m: \mathbb{R}_{+} \rightarrow \mathcal{M}_{i}$ such that (i) $m(0)=(\theta, \gamma)$, (ii) $m\left(x^{\prime}\right) \subset m(x)$ for all $x^{\prime}$ and $x$ such that $x^{\prime}<x$, and (iii) $C=P \circ m$ is continuous and differentiable at all $x \in \mathbb{R}_{+}$. The firms in the set $m(x)$ will be moved from region $i$ to region $j ; C(x)$ is their measure. For each $m(x)$, let $v(x)$ be the decline in region $i$ 's aggregate productivity when the firms are moved out of region $i$, and let 
$h(x)$ be the increase in region $j$ 's aggregate productivity gain when the firms are moved into that region. Since $C$ is continuous and differentiable, $v$ and $h$ are continuous and differentiable. Assuming that labour is reallocated to equalize the marginal product of labour across the firms in each region, the movement of the firms causes total output to rise by

$$
D\left(x, k^{*}\right)=F\left(Z_{j}\left(k^{*}\right)+h(x), N_{j}\right)-F\left(Z_{i}\left(k^{*}\right)-v(x), N_{i}\right)
$$

Taking the first-order derivative of $D$ with respect to $x$ and evaluating it at $x=0$ gives

$$
\begin{aligned}
\frac{\partial D\left(0, k^{*}\right)}{\partial x} & =\frac{\partial F\left(Z_{j}\left(k^{*}\right), N_{j}\right)}{\partial \theta_{j}} \frac{d h(0)}{d x}-\frac{\partial F\left(Z_{i}\left(k^{*}\right), N_{i}\right)}{\partial \theta_{i}} \frac{d v(0)}{d x} \\
& =\frac{d h(0)}{d x} k_{j}^{*}-\frac{d v(0)}{d x} k_{i}^{*}
\end{aligned}
$$

Since

$$
\theta_{j} k_{j}^{*}>\theta_{i} k_{i}^{*}
$$

for every firm that is moved between regions, this derivative is positive. That is, moving a small but positive measure of firms between the regions raises total output. Then $L$ does not maximize total output if $L$ is not measurably identical to $L\left(k^{*}\right)$, where where $k^{*}$ is some fixed point of $(7)$. Therefore, it is necessary condition for the output-maximizing location rule $L$ that $L$ must be measurably identical to $L\left(k^{*}\right)$, where $k^{*}$ is some fixed point of (7). Since there exists a unique fixed point $k^{*}$ of $(7)$, the necessary condition becomes the sufficient one for the output-maximizing location rule.

Proof of Theorem 1: P1 follows from Lemma 1. Given $R_{i}$, region $i$ 's problem is to find $\left(c_{i}, g_{i}\right)$ to maximize $s_{i}$ subject to $c_{i}+g_{i} \leq R_{i}$. Since $s_{i}$ is increasing, the constraint must hold with equality at a solution. Given the assumptions on $s_{i}, \mathrm{P} 2$ is both necessary and sufficient for $\left(c_{i}, g_{i}\right)$ to maximize $s_{i}$ subject to the constraint (2) Let $\left(c_{i}^{*}\left(R_{i}\right), g_{i}^{*}\left(R_{i}\right)\right)$ be the solution to this maximization problem. Since $s_{i}$ is concave, increasing, and twice differentiable, $s_{i}\left(c_{i}^{*}\left(R_{i}\right), g_{i}^{*}\left(R_{i}\right)\right)$ is increasing in $R_{i}$. Consequently, shifting resources from one region to another raises one region's welfare at the expense of the other region. Then any allocation of output that satisfies (1) can be part of a Pareto optimal allocation.

Definition: An offer is a winning offer if it is accepted by the firm. It is a matching offer if it would give the firm the same after-tax profits as the winning offer but is not accepted by the firm. 
Proof of Lemma 2: If region $i$ contains a set of firms that have no matching offers, and if this set has positive measure, region $i$ can increase its resources by slightly reducing its offers to these firms. Thus, condition 1 is a necessary condition for the absence of a revenue-increasing deviation. The remainder of the proof assumes that this condition holds, and proceeds in three parts. The first part describes the deviations open to region $i$. The second part shows that the second and third conditions hold if region $i$ has no resource-increasing deviation; and the third part shows that region $i$ has no resource-increasing deviation if all three conditions hold.

1. Region $i$ 's options are limited to one or both of the following: (a) reduce the offers to the firms in a set of positive measure, causing them to locate elsewhere; (b) raise the offers to the firms in a set of positive measure, causing them to choose region $i$. To describe (a), let $\mathcal{M}_{i}$ be the set of all subsets of $L_{i}$, and identify some $\left(\theta^{0}, \gamma^{0}\right)$ contained in $L_{i}$. Define a mapping $m_{0}: \mathbb{R}_{+} \rightarrow \mathcal{M}_{i}$ such that (i) $m_{0}(0)=\left(\theta^{0}, \gamma^{0}\right)$, (ii) $m_{0}\left(x^{\prime}\right) \subset m_{0}(x)$ for all $x^{\prime}$ and $x$ such that $x^{\prime}<x$, and (iii) $C_{0} \equiv P \circ m_{0}$ is continuous and differentiable at all $x \in \mathbb{R}_{+}$. The firms in the set $m_{0}(x)$ will be induced to leave region $i$. Their measure is $C_{0}(x)$. Define the functions:

$$
\begin{gathered}
A_{0}(x) \equiv \int_{m_{0}(x)} \theta_{i} d P \\
B_{0}(x) \equiv \int_{m_{0}(x)} \pi_{i}(\theta, \gamma) d P \\
z_{i} \equiv \int_{L_{i}} \theta_{i} d P
\end{gathered}
$$

To describe (b), let $L_{-i}$ be the set of firms that choose to locate in a region other than $i$, and let $\mathcal{M}_{-i}$ be the set of all subsets of $L_{-i}$. Choose some $\left(\theta^{1}, \gamma^{1}\right)$ contained in $L_{-i}$. Define a mapping $m_{1}: \mathbb{R}_{+} \rightarrow \mathcal{M}_{-i}$ such that (i) $m_{1}(0)=\left(\theta^{1}, \gamma^{1}\right)$, (ii) $m_{1}\left(x^{\prime}\right) \subset m_{1}(x)$ for all $x^{\prime}$ and $x$ such that $x^{\prime}<x$, and (iii) $C_{1} \equiv P \circ m_{1}$ is continuous and differentiable at all $x \in \mathbb{R}_{+}$. The firms in the set $m_{1}(x)$ will be induced to locate in region $i$, and their measure is $C_{1}(x)$. Define the functions:

$$
\begin{gathered}
A_{1}(x) \equiv \int_{m_{1}(x)} \theta_{i} d P \\
B_{1}(x) \equiv \sum_{j \neq i}\left(\int_{m_{1}(x) \cap L_{j}} \pi_{j} d P\right)
\end{gathered}
$$


Any deviation can be represented by choosing the functions $m_{0}$ and $m_{1}$ appropriately and by evaluating them at appropriate points, denoted $x_{0}$ and $x_{1}$ respectively. Since region $i$ can induce a firm to move to that region by matching the firm's best offer, its resources under a given deviation are

$$
\begin{aligned}
R_{i}\left(x_{0}, x_{1}\right)=\left(z_{i}+A_{1}\left(x_{1}\right)-A_{0}\left(x_{0}\right)\right) & r\left(\frac{N_{i}}{z_{i}+A_{1}\left(x_{1}\right)-A_{0}\left(x_{0}\right)}\right) \\
& -B_{1}\left(x_{1}\right)+B_{0}\left(x_{0}\right)-\int_{L_{i}} \pi_{i} d P+\sum_{j=1}^{I}\left(\int_{L_{j}} \gamma_{i} \pi_{j}(\theta, \gamma) d P\right)
\end{aligned}
$$

2. If $\partial R_{i}(0,0) / \partial x_{0}$ is positive, there exists some arbitrarily small but positive $\delta$ such that region $i$ could increase $R_{i}$ be reducing its offers to the firms in the set $m_{0}(\delta)$. Thus, region $i$ has no resource-increasing deviations only if

$$
\frac{\partial R_{i}(0,0)}{\partial x_{0}}=-A_{0}^{\prime}(0) r\left(\mu_{i}\right)+B_{0}^{\prime}(0) \leq 0
$$

for almost all $\left(\theta^{0}, \gamma^{0}\right)$, or equivalently, only if

$$
\theta_{i} r\left(\mu_{i}\right) \geq \pi_{i}(\theta, \gamma)
$$

for almost all $(\theta, \gamma)$ contained in $L_{i}$. Likewise, if $\partial R_{i}(0,0) / \partial x_{1}$ is positive, there exists some arbitrarily small but positive $\delta$ such that region $i$ could increase $R_{i}$ be raising its offers to the firms in the set $m_{1}(\delta)$. It follows that region $i$ has no resource-increasing deviations only if

$$
\frac{\partial R_{i}(0,0)}{\partial x_{1}}=A_{1}^{\prime}(0) r\left(\mu_{i}\right)-B_{1}^{\prime}(0) \leq 0
$$

for almost all $\left(\theta^{1}, \gamma^{1}\right)$, or equivalently, only if

$$
\theta_{i} r\left(\mu_{i}\right) \geq \pi_{j}(\theta, \gamma)
$$

for almost all $(\theta, \gamma)$ contained in $L_{j}(j \neq i)$. Thus, (8) and (9) are necessary conditions for the absence of a resource-increasing deviation in region $i$.

3. Since $A_{0}$ and $A_{1}$ are strictly increasing functions, the implicit function

$$
A_{1}\left(x_{1}\right)=A_{0}\left(x_{0}\right)
$$

can be written as either of the following strictly increasing functions:

$$
x_{1}=\phi\left(x_{0}\right)
$$




$$
x_{0}=\psi\left(x_{1}\right)
$$

The function $r$ is increasing, so information on the relative sizes of $A_{0}\left(x_{0}\right)$ and $A_{1}\left(x_{1}\right)$ helps to determine the signs of the partial derivatives of $R_{i}$. Specifically, by (8),

$$
\frac{\partial R_{i}}{\partial x_{0}} \leq-A_{0}^{\prime}\left(x_{0}\right) r\left(\mu_{i}\right)+B_{0}^{\prime}\left(x_{0}\right) \leq 0 \quad \text { if } A_{0}\left(x_{0}\right) \geq A_{1}\left(x_{1}\right)
$$

and by (9),

$$
\frac{\partial R_{i}}{\partial x_{1}} \leq A_{1}^{\prime}\left(x_{1}\right) r\left(\mu_{i}\right)-B_{1}^{\prime}\left(x_{1}\right) \leq 0 \quad \text { if } A_{1}\left(x_{1}\right) \geq A_{0}\left(x_{0}\right)
$$

To show that the stated conditions are sufficient for the absence of a resourceincreasing deviation, two cases must be considered.

Case 1. Assume that region $i$ wants to drive away the firms in the set $m_{0}\left(x_{0}^{*}\right)$ and attract the firms in the set $m_{1}\left(x_{1}^{*}\right)$, and that $A_{1}\left(x_{1}^{*}\right)$ is at least as large as $A_{0}\left(x_{0}^{*}\right)$. Equivalently,

$$
x_{1}^{*} \geq \phi\left(x_{0}^{*}\right)
$$

Then

$$
\begin{aligned}
& R_{i}\left(x_{0}^{*}, x_{1}^{*}\right)-R_{i}(0,0) \\
= & {\left[R_{i}\left(x_{0}^{*}, x_{1}^{*}\right)-R_{i}\left(x_{0}^{*}, \phi\left(x_{0}^{*}\right)\right]+\left[R_{i}\left(x_{0}^{*}, \phi\left(x_{0}^{*}\right)-R_{i}(0,0)\right]\right.\right.} \\
= & \int_{\phi\left(x_{0}^{*}\right)}^{x_{1}^{*}} \frac{\partial R_{i}\left(x_{0}^{*}, q\right)}{\partial x_{1}} d q+\int_{0}^{x_{0}^{*}}\left[\frac{\partial R_{i}(q, \phi(q))}{\partial x_{0}}+\frac{\partial R_{i}(q, \phi(q))}{\partial x_{1}} \phi^{\prime}(q)\right] d q
\end{aligned}
$$

The partial derivative in the first integrand is evaluated at pairs $\left(x_{0}^{*}, x_{1}\right)$ for which $x_{1} \geq \phi\left(x_{0}^{*}\right)$, so (11) implies that the first integral (if it is present) is non-positive. The partial derivatives in the second integrand are evaluated at pairs $\left(x_{0}, \phi\left(x_{0}\right)\right)$, so (10) and (11) imply that the second integral is also non-positive. Thus, a deviation of this type does not increase $R_{i}$.

Case 2. Assume again that region $i$ wants to drive away the firms in the set $m_{0}\left(x_{0}^{*}\right)$ and attract the firms in the set $m_{1}\left(x_{1}^{*}\right)$, but now assume that $A_{1}\left(x_{1}^{*}\right)$ is smaller $A_{0}\left(x_{0}^{*}\right)$. Equivalently,

$$
x_{0}^{*}>\psi\left(x_{1}^{*}\right)
$$


Then

$$
\begin{aligned}
& R_{i}\left(x_{0}^{*}, x_{1}^{*}\right)-R_{i}(0,0) \\
= & {\left[R_{i}\left(x_{0}^{*}, x_{1}^{*}\right)-R_{i}\left(\psi\left(x_{1}^{*}\right), x_{1}^{*}\right)\right]+\left[R_{i}\left(\psi\left(x_{1}^{*}\right), x_{1}^{*}\right)-R_{i}(0,0)\right] } \\
= & \int_{\psi\left(x_{1}^{*}\right)}^{x_{0}^{*}} \frac{\partial R_{i}\left(q, x_{1}^{*}\right)}{\partial x_{0}} d q+\int_{0}^{x_{1}^{*}}\left[\frac{\partial R_{i}(\psi(q), q)}{\partial x_{0}}+\frac{\partial R_{i}(\psi(q), q)}{\partial x_{1}} \psi^{\prime}(q)\right] d q
\end{aligned}
$$

Since (10) implies that the first integral is non-positive, and (10) and (11) imply that the second integral is non-positive, this kind of deviation does not increase $R_{i}$.

Proof of Theorem 2: The first step is to show that a vector of marketclearing wages exists, and that this vector is unique. A firm maximizes its profits by choosing the quantity of labour that satisfies the condition

$$
f^{\prime}\left(\frac{n_{i}}{\theta_{i}}\right)=w_{i}
$$

Let $\widetilde{n}_{i}\left(\theta_{i}, w_{i}\right)$ be the solution that solves the first-order condition above. Inverting this condition shows that

$$
\frac{n_{i}}{\theta_{i}}=x_{i}\left(w_{i}\right)
$$

for every firm in region $i$. Define the vector $\widetilde{k}(w) \equiv\left(\widetilde{k}_{1}(w), \ldots, \widetilde{k}_{I}(w)\right)$ such that

$$
\widetilde{k}_{i}(w)=r\left(x_{i}\left(w_{i}\right)\right) \quad \text { for all } i \in \mathcal{I}
$$

Lemma 2 shows that, under any wage vector $w$, a firm locates in the region in which its gross profits are highest, so the firms' locations are given by $L(\widetilde{k}(w))$. By $(13)$, a firm's demand for labour is

$$
\widetilde{n}_{i}\left(\theta_{i}, w_{i}\right)=\theta_{i} x_{i}(w)
$$

The aggregate demand for labour in region $i$ is found by integrating over the demands of the individual firms in that region:

$$
N_{i}^{D}=\left(\int_{L_{i}(\widetilde{k}(w))} \theta_{i} d P\right) x_{i}\left(w_{i}\right)=Z_{i}(\widetilde{k}(w)) x_{i}\left(w_{i}\right)
$$

The regional labour market clearing condition equates this demand to the supply of labour:

$$
x_{i}\left(w_{i}\right)=\frac{N_{i}}{Z_{i}(\widetilde{k}(w))}
$$


Using (14),

$$
\widetilde{k}_{i}(w)=r\left(\frac{N_{i}}{Z_{i}(\widetilde{k}(w))}\right)
$$

A vector of market-clearing wages exists if and only if there exists a vector $\widetilde{k}(w)$ such that this condition is satisfied for all $I$ markets, but the required vector $\widetilde{k}(w)$ is simply a fixed point of (7). Lemma 1 shows that this fixed point exists and is unique, so a vector of market-clearing wages exists and is unique. Furthermore, Lemma 2 implies that the locations of the firms and the distribution of labor across firms are measurably identical across equilibria because the market-clearing wage vector is identical across equilibria. Now consider the issue of Pareto optimality. All of the firms in a region equate their marginal products of labour to the market wage rate, so the marginal products of labour are equalized across firms. The uniqueness of the fixed point implies that $\widetilde{k}(w)$ is the same as $k^{*}$, so that any $L(\widetilde{k}(w))$ is measurably identical to $L\left(k^{*}\right)$ and hence P1 is satisfied. Since the governments use their lump-sum taxes to attain an optimal division of their resources between the public and private good, P2 is also satisfied. Therefore, the equilibrium allocation induced by any equilibrium is Pareto optimal.

Proof of Lemma 3: If the firms in $L_{i}$ that do not have matching offers constitute a set of positive measure, region $i$ could reduce its offers to these firms without losing them. This adjustment would cause $R_{i}^{g}$ to rise, and $R_{i}^{c}$ to fall by a smaller amount. Since a unit of $R_{i}^{c}$ is never more valuable than a unit of $R_{i}^{g}$, social welfare would rise. It follows that $\mathrm{E}$ ! is a necessary condition for the absence of a welfare-improving deviation. Assume that this condition holds, and define $m_{h}(x), A_{h}(x)$ and $B_{h}(x)(h=0,1)$ as in Lemma 2. Region $i$ 's resources when it abandons the firms in $m_{0}\left(x_{0}\right)$ and attracts the firms in $m_{1}\left(x_{1}\right)$ are given by the functions

$$
\begin{aligned}
& R_{i}^{g}\left(x_{0}, x_{1}\right)=\left(z_{i}+A_{1}\left(x_{1}\right)-A_{0}\left(x_{0}\right)\right) f\left(\frac{N_{i}}{z_{i}+A_{1}\left(x_{1}\right)-A_{0}\left(x_{0}\right)}\right) \\
&-\int_{L_{i}} \pi_{i}(\theta, \gamma) d P-B_{1}\left(x_{1}\right)+B_{0}\left(x_{0}\right) \\
& R_{i}^{c}\left(x_{0}, x_{1}\right)=\sum_{b=1}^{I}\left(\int_{L_{i}} \gamma_{i} \pi_{b}(\theta, \gamma) d P\right)
\end{aligned}
$$

Since $R_{i}^{c}$ is not affected by a deviation, social welfare is maximized by maximizing $R_{i}^{g}$. Proceeding as in Lemma 2 shows that E2 and E3 hold if region $i$ 
does not have a welfare-improving deviation, and that region $i$ does not have a welfare-improving deviation if E1-E3 hold.

Proof of Theorem 3: The existence of an equilibrium can be proved by showing the existence of the market clearing wage vector. Since every firm locates into a region where it can attain its highest gross profits, the market-clearing wage vector is unique and the same as the one proved in the corresponding part of the proof of Theorem 2. It immediately follows that the allocation of firms and the allocation of labour across firms are measurably identical across equilibria when the government can only impose the lump-sum tax on wages as when it can tax all of domestic income, so $(L, n)$ again maximizes total output. Item 2 follows from the non-negativity of each region's revenues: these revenues can be sufficient to provide the optimal quantity of public goods.

Proof of Lemma 4: The argument of Lemma 3 shows that E1 is a necessary condition for the absence of a welfare-improving deviation in region $i$. Assume that this condition holds, and define $m_{h}(x), A_{h}(x)$ and $B_{h}(x)$ $(h=1,2)$ as in Lemma 2. Social welfare in region $i$ under any given deviation is

$$
\widehat{\sigma}_{i}\left(x_{0}, x_{1}\right) \equiv S_{i}\left(\widehat{R}_{i}^{c}\left(x_{0}, x_{1}\right), \widehat{R}_{i}^{g}\left(x_{0}, x_{1}\right)\right)
$$

where

$$
\begin{aligned}
& \widehat{R}_{i}^{c}\left(x_{0}, x_{1}\right)=\left(z_{i}+A_{1}\left(x_{1}\right)-A_{0}\left(x_{0}\right)\right) \\
& \times\left\{f\left(\frac{N_{i}}{z_{i}+A_{1}\left(x_{1}\right)-A_{0}\left(x_{0}\right)}\right)-r\left(\frac{N_{i}}{z_{i}+A_{1}\left(x_{1}\right)-A_{0}\left(x_{0}\right)}\right)\right\} \\
&+\sum_{b=1}^{I}\left(\int_{L_{b}} \gamma_{i} \pi_{b}(\theta, \gamma) d P\right) \\
& \widehat{R}_{i}^{g}\left(x_{0}, x_{1}\right)=\left(z_{i}+A_{1}\left(x_{1}\right)-A_{0}\left(x_{0}\right)\right) r\left(\frac{N_{i}}{z_{i}+A_{1}\left(x_{1}\right)-A_{0}\left(x_{0}\right)}\right) \\
&-\int_{L_{i}} \pi_{i}(\theta, \gamma) d P+B_{0}\left(x_{0}\right)-B_{1}\left(x_{1}\right)
\end{aligned}
$$

If $\partial \widehat{\sigma}_{i}(0,0) / \partial x_{0}$ is positive, there exists an arbitrarily small but positive $\delta$ such that region $i$ can increase $s_{i}$ by reducing the offers to the firms in the set $m_{0}(\delta)$. Thus, region $i$ has no welfare-improving deviation only if this 
derivative is non-positive. This condition is satisfied if and only if

$$
A_{0}^{\prime}(0) r\left(\mu_{j}\right)\left[\frac{\varepsilon\left(\mu_{j}\right)}{M R S_{j}}+\left(1-\varepsilon\left(\mu_{j}\right)\right)\right] \leq B_{0}^{\prime}(0)
$$

for any $\left(\theta^{0}, \gamma^{0}\right)$, or equivalently, if almost every element of $L_{i}$ satisfies

$$
\theta_{j} r\left(\mu_{j}\right)\left[\frac{\varepsilon\left(\mu_{j}\right)}{M R S_{j}}+\left(1-\varepsilon\left(\mu_{j}\right)\right)\right] \leq \pi_{i}(\theta, \gamma)
$$

Likewise, if $\partial \widehat{\sigma}_{i}(0,0) / \partial x_{1}$ is positive, there exists an arbitrarily small but positive $\delta$ such that region $i$ can increase $s_{i}$ by raising the offers to the firms in the set $m_{1}(\delta)$. Thus, region $i$ has no welfare-improving deviation only if this derivative is non-positive. This condition is satisfied if and only if

$$
A_{1}^{\prime}(0) r\left(\mu_{i}\right)\left[\frac{\varepsilon\left(\mu_{i}\right)}{M R S_{i}}+\left(1-\varepsilon\left(\mu_{i}\right)\right)\right] \geq B_{1}^{\prime}(0)
$$

for any $\left(\theta^{1}, \gamma^{1}\right)$, or equivalently, if almost every element of $L_{h}(h \neq i)$ satisfies

$$
\theta_{i} r\left(\mu_{i}\right)\left[\frac{\varepsilon\left(\mu_{i}\right)}{M R S_{i}}+\left(1-\varepsilon\left(\mu_{i}\right)\right)\right] \geq \pi_{h}(\theta, \gamma)
$$

Combining (16), (17) and the matching requirement gives the lemma.

Proof of Lemma 5: Define the variables

$$
\beta_{i} \equiv \alpha+\frac{1-\alpha}{M R S_{i}} \quad \text { for all } i \in \mathcal{I}
$$

and let $\beta$ be the vector $\left(\beta_{1}, \ldots \beta_{I}\right)$. In any equilibrium a firm goes to region $i$ only if

$$
\theta_{i} k_{i} \geq \theta_{j} k_{j} \quad \text { for all } j \in \mathcal{I}
$$

However, Lemma 4 implies that, in equilibrium, a firm goes to region $i$ only if

$$
\theta_{i}\left(\frac{N_{i}}{Z_{i}(k)}\right)^{1-\alpha} \beta_{i} \geq \theta_{j}\left(\frac{N_{j}}{Z_{j}(k)}\right)^{1-\alpha} \beta_{j} \quad \text { for all } j \in \mathcal{I}
$$

Then an equilibrium distribution of firms across regions is described by $L(\widehat{k}(\beta))$, where $\widehat{k}(\beta)$ is the solution to the equation system

$$
k_{i}=\left(\frac{N_{i}}{Z_{i}(k)}\right)^{1-\alpha} \beta_{i} \quad \text { for all } i \in \mathcal{I}
$$


By FP1, $\widehat{k}(\beta)$ exists and is unique for every strictly positive $\beta$. The functions $\widehat{k}(\beta)$ are continuous. As well, $Z_{i}(\widehat{k}(\beta))$ is continuous in $\beta$, and by FP1, it is positive for every strictly positive vector $\beta$. It follows that the functions $R_{i}^{c}(\beta)$ and $R_{i}^{g}(\beta)$ are also continuous. Since $L_{i}(\widehat{k}(\beta)$ is non-empty for every strictly positive vector $\beta, R_{i}^{c}(\beta)$ is positive and $R_{i}^{g}(\beta)$ is non-negative for every strictly positive vector $\beta$. Now note that $M R S_{i}$ is a continuous function of the region's resources and hence a continuous function of $\beta$. Write this relationship as

$$
M R S_{i}=\psi_{i}(\beta)
$$

and consider the mapping

$$
\phi_{i}(\beta)=\alpha+\frac{1-\alpha}{\psi_{i}(\beta)} \quad i \in \mathcal{I}
$$

Define the set

$$
\mathbb{D} \equiv[\alpha, 1]^{I}
$$

The mapping $\phi: \mathbb{D} \rightarrow \mathbb{D}$ is continuous and well-defined, so the mapping has a fixed point $\beta^{*}$. All of the elements of an equilibrium can be inferred from $\beta^{\circ}$. The equilibrium $L$ is $L\left(\widehat{k}\left(\beta^{\circ}\right)\right)$ or is measurably identical to it. The equilibrium allocation of labour is measurably identical to

$$
n(\theta, \gamma)=\theta_{i}\left[\frac{N_{i}}{Z_{i}\left(\widehat{k}\left(\beta^{\circ}\right)\right)}\right] \quad i \in \mathcal{I}
$$

Each region's wage is equal to its equilibrium marginal product of labour. Government $i$ 's revenues are $R_{i}^{c}\left(\beta^{\circ}\right)$ and $R_{i}^{g}\left(\beta^{\circ}\right)$, and region $i$ 's consumption of private and public goods is $c_{i}\left(R_{i}^{c}\left(\beta^{\circ}\right), R_{i}^{g}\left(\beta^{\circ}\right)\right)$ and $g_{i}\left(R_{i}^{c}\left(\beta^{\circ}\right), R_{i}^{g}\left(\beta^{\circ}\right)\right)$.

Total output is maximized in an equilibrium if and only if there is some positive $\lambda$ such that, for all $i \in \mathcal{I}, \widehat{k}_{i}\left(\beta^{\circ}\right)=\lambda k_{i}^{*}$ where $k^{*}$ is the solution to $(7)$. Assume that every marginal rate of substitution is the same. By (18), every element of $\beta^{\circ}$ is equal to some $\lambda$, where $\alpha<\lambda \leq 1$. Since $Z_{i}(k)$ is linearly homogeneous, and since $\widehat{k}(\beta)=k^{*}$ when every element of $\beta$ is equal to $1, \widehat{k}_{i}\left(\beta^{\circ}\right)=\lambda k^{*}$ so that total output is maximized. Now suppose that total output is maximized, implying $\widehat{k}\left(\beta^{\circ}\right)=\lambda k^{*}$. Evaluating (19) at $\lambda k^{*}$ determines a unique vector $\beta^{\circ}$. Since it has already been shown that $\widehat{k}\left(\beta^{\circ}\right)=\lambda k^{*}$ when every element of $\beta^{\circ}$ is equal to $\lambda$, this is the unique solution for $\beta^{\circ}$. Thus, total output maximization implies that every element of $\beta^{\circ}$ is the same and hence every element of $M R S$ is the same. 
Proof that the symmetric allocation is an equilibrium allocation: For concreteness, it will be shown that region 1 has no welfare-improving deviations; the demonstration for region 2 is identical. Define the functions $m_{0}\left(x_{0}\right)$ and $m_{1}\left(x_{1}\right)$ as in Lemma 2. Then

$$
\begin{gathered}
A_{0}\left(x_{0}\right)=\int_{m_{0}\left(x_{0}\right)} \widehat{\theta} d P \\
A_{1}\left(x_{1}\right)=\lambda \int_{m_{1}\left(x_{1}\right)} \widehat{\theta} d P \\
B_{0}\left(x_{0}\right)=\alpha \lambda \int_{m_{0}\left(x_{0}\right)} \widehat{\theta} d P=\alpha \lambda A_{0}\left(x_{0}\right) \\
B_{1}\left(x_{1}\right)=\alpha \lambda \int_{m_{1}\left(x_{1}\right)} \widehat{\theta} d P=\alpha A_{1}\left(x_{1}\right)
\end{gathered}
$$

Using these expressions and the equilibrium profits to evaluate the region's resources gives

$$
\begin{gathered}
\widehat{R}_{1}^{c}\left(x_{0}, x_{1}\right)=(1-\alpha)\left[1+A_{1}\left(x_{1}\right)-A_{0}\left(x_{0}\right)\right]^{\alpha}+\alpha \lambda \\
\widehat{R}_{1}^{g}\left(x_{0}, x_{1}\right)=\alpha\left[1+A_{1}\left(x_{1}\right)-A_{0}\left(x_{0}\right)\right]^{\alpha}+\alpha \lambda \int_{L_{1}} \gamma(\widehat{\theta}) \widehat{\theta} d P+\alpha \lambda A_{0}\left(x_{0}\right)-\alpha A_{1}\left(x_{1}\right)
\end{gathered}
$$

Since the region's resources under any deviation depend only upon the values taken by the functions $A_{0}$ and $A_{1}$, they can be expressed directly in terms of these values:

$$
\begin{gathered}
\widetilde{R}_{1}^{c}\left(A_{0}, A_{1}\right)=(1-\alpha)\left(1+A_{1}-A_{0}\right)^{\alpha}+\alpha \lambda \\
\widetilde{R}_{1}^{g}\left(A_{0}, A_{1}\right)=\alpha\left[1+A_{1}-A_{0}\right]^{\alpha}+\alpha \lambda \int_{L_{1}} \gamma(\widehat{\theta}) \widehat{\theta} d P+\alpha \lambda A_{0}-\alpha A_{1}
\end{gathered}
$$

A deviation $\left(A_{0}^{\prime}, A_{1}^{\prime}\right)$ in which $A_{1}^{\prime} \geq A_{0}^{\prime}>0$ is dominated by the deviation $\left(0, A_{1}^{\prime}-A_{0}^{\prime}\right)$, because the latter deviation gives the same $R_{1}^{c}$ but a higher $R_{1}^{g}$. A deviation $\left(A_{0}^{\prime}, A_{1}^{\prime}\right)$ in which $A_{0}^{\prime} \geq A_{1}^{\prime}>0$ is dominated by the deviation $\left(A_{0}^{\prime}-A_{1}^{\prime}, 0\right)$ for the same reason. It is therefore sufficient to show that there are no welfare-improving deviations $\left(A_{0}, A_{1}\right)$ in which exactly one of $A_{0}$ and $A_{1}$ is positive. Consider first deviations in which the region attracts firms. Differentiation gives

$$
\frac{\partial \widetilde{R}_{1}^{c}\left(0, A_{1}\right)}{\partial A_{1}}=\alpha(1-\alpha)\left(\frac{1}{1+A_{1}}\right)^{1-\alpha}>0
$$




$$
\frac{\partial \widetilde{R}_{1}^{g}\left(0, A_{1}\right)}{\partial A_{1}}=\alpha^{2}\left(\frac{1}{1+A_{1}}\right)^{1-\alpha}-\alpha<0
$$

Both derivatives decline as $A_{1}$ rises, so the region gives up the smallest amount of $R_{1}^{g}$ for another unit of $R_{1}^{c}$ when $A_{1}$ is equal to 0 , and at this point, one unit of $R_{1}^{g}$ is given up to obtain one more unit of $R_{1}^{c}$. Since $M R S_{1}$ is never less than 1 , this trade-off does not raise welfare. Now consider deviations in which the region abandons firms. Differentiation gives

$$
\begin{gathered}
\frac{\partial \widetilde{R}_{1}^{c}\left(A_{0}, 0\right)}{\partial A_{0}}=-\alpha(1-\alpha)\left(\frac{1}{1-A_{0}}\right)^{1-\alpha}<0 \\
\frac{\partial \widetilde{R}_{1}^{g}\left(A_{0}, 0\right)}{\partial A_{0}}=-\alpha^{2}\left(\frac{1}{1-A_{0}}\right)^{1-\alpha}+\lambda \alpha
\end{gathered}
$$

Abandoning firms is clearly not welfare-improving if the second derivative is also negative, so imagine that it is positive. Both derivatives decline as $A_{0}$ rises, so the region gets the largest amount of $R_{1}^{g}$ in exchange for a unit of $R_{1}^{c}$ when $A_{0}$ is equal to zero, and at that point, less than a unit of $R_{1}^{g}$ is obtained in exchange for one unit of $R_{1}^{c}$. Since $M R S_{1}$ is never less than 1 , this trade-off does not raise welfare.

\section{References}

Black, D. and W. Hoyt, 1989, Bidding for firms, American Economic Review 79, 1249-1256.

Bond, E. and L. Samuelson, 1986, Tax holidays as signals, American Economic Review 76, 820-826.

Burbidge, J., K. Cuff and J. Leach, 2006, Tax competition with heterogeneous firms, Journal of Public Economics 90, 533-549.

Doyle, C. and S. van Wijnbergen, 1994, Taxation of foreign multinationals: a sequential bargaining approach to tax holidays, International Tax and Public Finance 1, 211-225.

Hamada, K., 1966, Strategic aspects of taxation on foreign investment income, Quarterly Journal of Economics 80, 361-375.

King, I., R. P. McAfee and L. Welling, 1993, Industrial blackmail: dynamic tax competition and public investment, Canadian Journal of Economics 26, 590-608.

Wilson, J., 1999, Theories of tax competition, National Tax Journal 52, 269-304. 